\title{
Electronic Signature and Electronic Contract, Comperative Aspect of Kosovo and Developed Countries
}

\author{
Islam Qerimi \\ MSc, Legal Consultat at Law Tech
}

\section{Abstract}

The study defines the advent of new technologies such as electronic contract and Electronic signature and other networks that have had impanct in changeing the business world wide and provided the trading processes in e-business more efficiency. In this article we will discuss about Electronic Constract and Electronic Signature in developed countries, how they have regulated this issue and when did it started to be used, wich do the positive and negative aspects, where Kosovo can benifite, know that in Kosovo is still not regulated with a law. We will focus on meeting the needs of the community in kosovo to have a law that Regulats the use of Electronic Contracts and Electronic Signature and trying to solve their problems in doing business world wide.

Keywords: Electronic Conctract, Electronic Signature, Eu-Directives, Kosovo and Developed Countries, Click Wrap, Brows Wrap.

\section{Introduction}

The Internet and digital technology are transforming our lives, everyday with the paces in a dimension of a real revolution. These fast and deep transformations are now being considered worldwide as the second most important revolution behind the industrial one. Using e-mail application for various services that different institutions and companies are offering to citizens enables lowering costs of printing, color, archiving requiring considerable space, and is also faster than service, and more quality.

While in terms of electronic contracts, they have managed to get a significant place in the development of legal relations between businesses, especially in electronic commerce, in many countries, the use of electronic contracts is increasing, but it is very important to deal in two aspects of electronic contracts, what are the advantages of its use, and what are the risks of electronic contracts, it is also important to address the characteristics of electronic contracts and what the factor is being made today in the development of business relations. 
We will also address e-Governance, what it means, what is being practiced, and why it is important for a country as well as what is involved in e-governance, how are they approaching the digitalization trend, Kosovo and Albania. All of these will be dealt with based on our legislation, European Union directives, but special focus will be on the world practice of how are developing signatures, electronic contracts and e-governance, taking into accounts how they have found space worldwide in electronic contracts.

\section{Methodology}

The methodology used in the realization of this study is combined with the research, comparative, historical methods, although it is not the case that the electronic contract has a long history, but there is enough history, as well as methodical analysis or analytics, is used.

In this study we will refer to the facts collected from the materials prepared in recent years, from various laws, scientific papers, researches and various articles that have been made public, regarding the contract and the electronic signature, which is a very topic important to facilitate the development of international businesses.

\section{Contract}

The increasingly sophisticated economic relations, adapting to the time and technology that is becoming more useful everyday, has made the contract a vital asset for the development and advancement of businesses, seeing this development extremely fast, and with global proportions, different contracts have also emerged.

The main legal form in which economic work is performed are contracts. The great development of contemporary science and technology is also manifested in the everincreasing number of contracts that should facilitate and simplify the relationship and realization of legal affairs (N.Dauti,2012)

The contract is a legal work for which the consent of the participating entities is required. As contract terms are:

- contracting ability;

- Reconciliation of will;

- Contracts;

- Legal basis of the contract (N.Dauti, 2012).

According to the Kosovo Law on Obligations, Article 16 states that "the contract is concluded when the contracting parties have agreed to the essential elements".

Field of Contract Implementation

The contract as a contracting form applies almost too all branches of law, except in criminal law. In the labor law, the contract finds expression in labor relations, as in 
contracts between the employer and the employee, as well as in the collective labor contract. In economic law, contracts for the circulation of goods and the provision of services are mostly used. In financial law the contract applies to the arrangement of various financial transactions. Public international law through contract regulates relations between states. But it should be noted that the contract is mostly used in the right of obligations (N.Dauti, 2012).

\section{Principle of contract freedom}

The principle of contract freedom is an opportunity for the participants in the relationship of duty to regulate their mutual free will to regulate the mutual legal relations of the obligations. More specifically, the principle of freedom of contract means:

that every subject of the right freely choose to bind or not conclude the contract;

that every subject of the right freely chooses the person (partner) to whom he / she will sign the contract;

That the subjects of the right freely determine the content of the contract the form and manner of its attachment;

That the subjects of the right freely decide on the change and the ways of termination of the contract;

In case the contract is concluded between subjects with different citizenship, the subjects of the right can freely choose the legislation that will be applied in their contract (N.Dauti, 2012).

As can be seen above, we have a description of the main terms or principles of contract freedom, where these principles are the main basis of a contract and are vital to the implementation of a legal contract, these conditions protect both parties from eventual damage from the contract, and also gives you the freedom of contracting that is guaranteed by the applicable laws in the respective countries, these conditions are also essential for the electronic contract as the subjects themselves choose the way they want to enter into a contract or reach an agreement.

Restricting the freedom of contracting in view of the conclusion of the contract in general Freedom of contracting is limited by the constitutional principles and the principles of the law itself, the cases of limiting the freedom of contracting:

Participants in the relationship of duty are free to regulate their relations according to their will, in accordance with the ordinance, public order and good doctrines.

Limitation of contractual freedoms through the legal obligation to enter into a contract (eg: car insurance contract, compulsory insurance of passengers, purchase of a border policy, etc). 
Economic entities involved in hotel services should enter into a contract with persons who are directed to use their services (the hotel can not refuse the client for any serious reason other than objective reasons).

Restricting the freedom of contracting in view of the choice of the contracting party (if the subject which you have entered into a contract is a monopoly on the market, then we are dealing with limitation).

Restriction of contract freedom through pre-emption right (the seller of agricultural land is obliged to start offering it for purchase to the person who has the right of pre-emption and then others, this restriction has to do with regard to the choice of the contracting party)

Restricting the freedom of contracting can also be made in terms of the content of the contract, so that the contracting parties can not change anything (the contract on the loan is compiled by the bank, the interest rate is set, the contract content, and the borrower in this case has only possibility of selection, sign or not)

Restricting the freedom of contracting is also done through the contract of the contract where the content of the contract is compiled irrespective of the will of the parties (international oil sales, contract for postal services etc.)

Limiting the freedom of contracting through formwork contracts (contract for the sale of real estate, construction contract, deposit etc.)

Restricting the freedom of contracting through collective bargaining (all individual labor contracts must be in accordance with the collective bargaining agreement or not contain less favorable provisions for the contracting parties)

Restriction of contract freedom when the validity of the contract requires the granting of consent (the guardian gives consent that the care enters into contractual relations), (Granit Curri, 2015)

Expression of will - the will to conclude a contract can be expressed in different ways: in words, gestures, or other behaviors. Expression of will is expressly expressed and indirect will expressed. Indirect desire comes to the fore when a person with their behaviors implies that he wants to conclude a contract.

Negotiations - In many cases, the conclusion of a contract precedes the negotiations. Negotiations do not contain supply elements, so they do not have a binding character (Nerxhivane Dauti, 2004).

Time and place of conclusion of the contract - As the time of the conclusion of the contract is considered the moment when the bidder reaches the statement that the other party accepts the offer. As a place of contract award is considered the country in which the bid was made, respectively the place in which the bidder has the seat or the place in which the bidder had the place of residence at the time the bid was made. 
Offer - Offer is a legal institution that has a mandatory character. The offer is a proposal for connection of the contract to a particular person, which in itself contains all the essential elements of the contract, so that the contract can be concluded upon acceptance of the contract. The offer may also be general when you are addressing some people. The legal bid effect is found in the production of the contract as the main purpose. The issue of bid revocation is the right of the one who has also offered. To make an offer or to sign a contract, the law does not foresee any form as a rule (Nerxhivane Dauti, 2004).

Some promises are made implicitly by the words or actions of the bidders / promises. For example, if Bob says to John: "I will wash and detail your car at 3:00 p.m today, if you bring it to my house, and if you pay me \$50," then John brings his car to the house Bob at 3 o'clock in the morning and let him say nothing, then John has probably made an implied promise to pay Bob \$ 50 for washing and detailing his car (Charles H. Martin, 2013).

Bid acceptance - the offer is considered to have been accepted when the Bidder receives the bidder's statement that he accepts the Bid. Also, the offer is treated as accepted even when the bidder sends the item or pays the price. Bid submission methods are usually dictated by how the bidder wishes the bidder to accept the bid or making a promise to do - facere or doing something required by the bidder or bidder. For example, if John says to Bob, "I will pay you \$ 50 if you promise to wash and detail my car at 3:00 pm", John wants Bob to promise to do this job and do the promised job. This work which as a promise has a promise-for-a-promise is called a "bilateral" contract (Charles H. Martin, 2013).

Pre-contract - is a contract with which the obligation to enter into another contract is called the main contract.

Contract Object - The object of the contract may be a grant, action, inaction or patience.

Failures of will - The flaws of will are presented as: threat; essential mistake; Motivation of contracts without compensation; dispute; indirect declaration; fraud, fictitiousness.

\section{Electronic contracts and electronic signatures}

The Electronic Contract is one of the most obvious examples of how information and communication technologies (ICTs) can contribute to economic growth. It helps countries improve trade efficiency and facilitate the integration of developing countries into the global economy. This allows businesses and entrepreneurs to become more competitive. But knowing that an instrument (electronic contract) is powerful is not enough to ensure it is used best, we need to understand how it works, how to use it, and find creative ways for them putting this knowledge in practice, spreading it extensively and maximizing its power, Ronald Lee, (R.lee, 1998) who was one of the first to initiate electronic contracts as a concept more than a decade on first. 
E-contracts are contracts that are executed and enacted by a software system in the sense that they are not concluded by face to face communications i.e. the "seller and buyer" or "supplier and consumer" do not meet in person to form, negotiate and execute the terms of their contract. Distance contracts is a type of e-contract because they are contracts concerning goods or services concluded between a supplier and a consumer under an organised distance sales which for the purpose of the contract, makes use of one or more means of distance communications such as internet, e-mails, telephones and so on up to and including when the contract is concluded (Lawteacher.net, June 2018).

Traditionally, when people have contractual agreements with one another, they have submitted a document, a physical copy signed by both parties, which is physically delivered, personally by the parties or via post, while over time and with increasing demand for exchange of goods and services between different countries, there is a growing demand for a faster way in order to overcome the barriers of distance and time.

For a contract to be formulated in a valid manner, certain elements must be completed, namely:

1. There must be an offer to determine the terms of the contract;

2. A clear receipt of the offer must be communicated to the person making the offer;

3. The contract must be supported by the review, eg; payment of the price;

4. Parties should aim to establish legal relationships;

5. All parties should have the legal capacity to carry out the transaction (Bateman Battersby, 2018).

However, in addition to the usual requirements for a paper contract, an electronicallycontracted contract is legally valid if:

1. The contract is preserved appropriately and can be achieved after signing; and

2. There has been consent between the parties to obtain information electronically, expressly or with implications.

One of the issues for electronic contracts is related to electronic signatures and it is the question of identifying a request for a purpose to establish contractual relations between the parties electronically, by signing the electronic parties the parties have the legal certainty that the contract concluded between the parties will be respected and will be legally valid.

Language and formal contracting procedures, employing technology for further standardization of certain classes of contracts in order to reduce transaction costs and contracting time is referred to as "Electronic Contracts". The first versions of the idea 
were based on Electronic Data Exchange (EDI) as a communication medium. Since then, electronic contracts have evolved along with electronic communications.

\section{Legal information:}

The legal information that we propose directs the whole negotiation process and addresses the concerns over the legality of the transactions executed while using the electronic contract on the Internet.

Consumers in a distance selling contract for goods or services are entitled to certain rights which they can enforce in the advent of a dispute that may evolve in the contract and these rights which are provided by different laws includes;

Right of withdrawal

Right of cancellation

Right to refund and reimbursement of sums paid

Right to rescind the contract

It is also important to understand that these consumer rights are subject to some exceptions because it is not all types of goods these rights applies to and such goods will be considered in relation to the goods that were ordered. Where the supplier complies with regulation 8 , the cancellation period ends on the expiry of the period of seven working days beginning with the day after the day on which the consumer receives his goods (Lawteacher.net, June 2018).

The legal information that helps in the formation of contracts is listed in. There are two methods by which information can be accessed:

1.1. Legal Information Websites - the electronic versions of some States as well as International Laws, which can be accessed via the Internet or for a subscription or nonpayment fee. The purpose of subscribing to websites is not only to provide more electronic versions of laws and regulations, but also to create various forums that they could discuss with professionals from different fields for discussion purposes who could make a lot of recommendations for the users of these forums, in order to have as much information as possible about electronic contracts, while in the form of contracts, these sites could be a reference tool.

1.2. A particular contract form, or contracts, terms and conditions that accompany or are part of commercial documents used for the purpose of purchases or various transactions, have become the form of a contract model (Bled 2001).

\section{Legal Infrastructure of the Electronic Contract}

Many governments are developing legal infrastructure for monitoring and regulating transactions that are carried out through the Internet. As a change of plan, trading initiatives like Bolero are giving consumers an opportunity to utilize the legal 
infrastructure they have developed and even make it mandatory for customers to sign and respect the rules when using these services.

In Bolero's (Bolero) heart is a unique legal infrastructure, the Bolero regulation. It connects users to a common set of rights and obligations in the electronic world (paperless).

It operates in accordance with national legal systems and international conventions.

The Bolero regulation is the result of one of the greatest legal feasibility in the world studies conducted by leading legal practitioners in the world trade law.

The rule drawn up by Bolero can be compared to that of a private contract. It does not neglect any of the trade agreements that are present in a contract. Instead, by signing the regulation, a user is responsible for the content of electronic documents sent through the Bolero workspace. Looking at the advancement that is taking place in different world countries, such as the United States or the European Union countries, whose main focus is to create more favorable business conditions, with a view to increasing trade international, respectively export of the products of the respective countries, therefore Kosovo and generally the Balkan countries should have a clear vision about how to design the legal path for the most advanced and safer use of the Electronic Contract and Signature electronics. Building a sustainable and advanced legal infrastructure would be one of the main priorities that the Kosovo government would have to deal with in the coming years, adaptation to the electronic system for the state of Kosovo would not be very difficult given that $65 \%$ of the population are of young age, and easily adapt to changes and advances in the electronic system (bolero).

There are different laws or legislations that govern e-contract most of which provide certain forms of redress and protection for parties to a contract most especially the consumer and they include;

The consumer protection (Distance Selling) Regulations 2000

The Electronic Commerce (EC Directive) Regulation 2002

Directive 2000/31/EC on electronic commerce

Directive 97/7/EC on consumer protection and distance contracts

Rome 1 convention on (contractual obligations)

There are also other laws which protect consumer rights with regards to distance selling contracts such as Unfair contract terms Act (1977) and the Unfair terms in consumer contracts regulations which applies in situations where the terms and conditions of the contract are not fair to the consumer and also to prevent significant imbalance in the rights and obligations of the parties to a contract, Sales of goods Act (1979) which gives the consumer the right to return the goods if there are not fit for their purpose and must be carried out within a reasonable time, Brussels 1 which protects the consumer when 
conflict of laws and jurisdiction issues arise and provides that 'where there is a dispute as to whose law will apply with regards a dispute between both parties, the applicable law will be the law of the consumers "habitual residence" if the supplier directs his activities to that country by any means and even if the parties choose a different law, it should not deprive the consumer of their mandatory laws" because they are of the opinion that the consumer is the weaker party, Uncitral model law and so on (Lawteacher.net, June 2018).

Electronic commerce is focused on business among large companies or in consumeroriented business online. The MEMO (Mareike Schoop) project tries to close the gap between these two areas by supporting e-commerce between small business and small business. Therefore, an electronic brokerage system is being developed which supports the research, negotiation and fulfillment stages of business partners, so in 1999-2001 it qualified as prof. Mareike Schoop, Ph.D, the time when the first legal structures about the advancement of electronic contracts began, and the big project where the participants of the project were the Netherlands, ABN-AMRO-Bank as project coordinator, Infolab of the University of Tilburg (NL), Origin of Spain, and several user groups including the Aachen Chamber of Commerce (IHK Aachen). The project started in January 1999 to complete in June 2001.

\section{Preparation of the Electronic Contract:}

3.1. In the case of negotiations where two or more parties are involved, several different versions of contracts are prepared until it brings to us a final agreement Means that facilitate the preparation of different versions of contracts as it may be. Contract Design - are some websites that are free of charge to assist in the drafting of electronic contracts that are part of the electronic contract system, the way these websites operate is that they pose some questions to which the user should answers you and then, the site automatically turns it into a standard form of electronic contract. these programs or pages are available to online users.

\section{Supporting the Decision}

This category includes functions that provide intelligent support to users while drafting contracts. In support of the decision tools should be made available through the outsourcing outsourcing process provided maximum support for users to make final decisions, which falls in cases where there are any ambiguities or do not understand any clause then through electronic forms the program be able to interpret the meaning of legal provisions or have a sub page where it can be linked and request additional clarifications (bled, 2001).

Electronic contracts and electronic signatures are as legitimate and enforceable as traditional contracts which are written on paper and signed into it, the law which made it possible for electronic contracts to be part of the global market was the International Act of Global Trade and Electronic Signatures (ESGICA), known as federal legislation 
adopted in 2000, has made electronic contracts as legitimate as paper contracts themselves, this was a welcome news for all businesses, dealing with internet businesses, especially those companies that provided financial services, or insurance companies as well as those of household customer services and many other companies. The law has also assisted in the so-called Business with Business (B2B), which has been a necessity for businesses to be able to place orders for supply and to perform Internet services. This step has been a very important step since it has directly impacted on reducing business expenses and also lowering the cost to the customer (nolo).

So the electronic contract is an agreement created and signed in electronic form - in other words, there is no need to use printed papers. For example, you can write a contract on your computer and send it by email, a business associate, and the same by email, accepted by the business associate who signed it by electronic signature and this shows the receipt of conditions and expresses his will to conclude the contract.

Contracts are merely an agreement between the parties, creating obligations that need to be enforced legally.

An electronic contract should contain:

Clear identification of contracting parties

The terms and conditions of the proposer or tenderer, presented in a clear and accurate manner.

The requested party or the receiving party must express its willingness to accept the contract at will.

And then the interactions between the parties for the execution of the contract, such as payment, delivery of goods or some other service, must begin.

Clear indication of contract validity (Michael Gisler).

The contract must have a valid signature from the parties involved in the contract confirming the acceptance of the obligations and the rights set forth in the contract. The signature must be accompanied by a date indicating the commencement of the validity of that contract.

\section{Form of Electronic Contracts}

There are many forms of electronic contracts but I will only mention two of the most important ones:

\section{Click wrap (dashfarrow) \\ II. Brows wrap}

I. In contrast to a Clickwrap Agreement is a web site requiring customers or users to first view the terms of an agreement by reading them, and then finally agreeing to the terms. 
A ClickWrap Agreement is an electronic contracting tool with the user who appears at the end of a product. The terms and conditions of the Clickwrap Agreements are displayed on the same page as they should be accepted with "I Agree" (I agree) (James Douglas)

II. A Brows wrap agreement is when the terms of a contract or agreement are placed on a website, but often these conditions may be placed in a link when it is sent to the terms of the contract, so it is almost the same as saying we have entered into a super market, and in a certain part, the super market noticeable part of the consumer rights. So in this type of contract, the customer himself has to express more interest in the contract he accepts by clicking on the link and browsing the terms of the contract he accepts.

\section{Why Use the Term "Wrap"}

- If you bought a software program in the 80's or 90's it came wrapped in a thin layer of cellophane. It contained the floppy disks or CDs and a copy of the software license. These licenses were deemed "shrinkwrap" licenses.

- After the boom of the World Wide Web, software was delivered online and the licenses used retained the term"wrap", becoming "browsewrap" or "clickwrap"licenses (Mackenzie Hughes).

Thi is how it started long time a go to get the names that now we use everyday.

Judges, generally recognize the sellr's shrink-wrapped terms as an "Offer", and the buyr's acts, of opening the pacage and keeping the product beyond the return period, as an "acceptance (Charles H. Martin, 2013).

\section{What are Clickwrap and Browsewrap Licenses?}

\section{Clickwrap Licenses}

A software license (for actual software, website, application, etc.) that requires the user to affirmatively click on a button or checkbox with a term such as "I Agree", prior to use. - Sometimes called a "click-through" or "click-to-accept" licence

Users usually have opportunity to scroll through and review the terms prior to assent.

If the user does not agree with the terms he or she cannot precede, their only choice then is to not click on the "I Agree" button and not use the software.

Example: - By clicking on the "I Agree" button you are agreeing to be bound by the following terms and conditions, that where writen by the company.

\section{Browsewrap Licenses}

Browsewrap agreements are software licenses that do not require affirmative consent other than the user's initial or continued use of the software, website, or application. 
The use combined with the knowledge of the terms and conditions of the browsewrap license are what constitute the user's assent.

Generally, courts will enforce browsewrap licenses only if the user had adequate and reasonable notice of the license terms.

Clients may want these licenses small, non-invasive and out of the way so they won't scare off potential users. You'll want the opposite, and may need to educate your client as to why its important. Drafting, maintaining and updating these licenses can create a perfect storm of legal, design and programming work. To draft and maintain these licenses properly you'll have to work closely with your client and their technical team to initially set up the license and for any updates (version 1.0, 2.0, etc.), thi sis how people know more about how to use click and browswrap, without having trubles with law.

Like any software licenses, clickwrap and browsewrap licenses are formal contracts that contain property rights. Being contracts, traditional rules of contract law still apply.

Most cases hinge on whether there was (1) either actual or constructive notice or (2) assent by the user.

Whether the user of the software actually knew, impliedly knew, or should have reasonably known, about the terms of the license before he or she clicked to agree or used the software.

\section{Implementing Online Agreements}

In recent courts that have decided how to deal better with the different types of online deals. In general, courts have been hesitant to implement Browse-wrap deals, giving them more fairness and allowing the implementation of the Clickwrap Agreements. The reason for this is that through the click wrap notice to the customer or user in any kind of deal is easier. Courts have argued that users are more likely to be aware of all terms and conditions when they are required to read and accept terms and conditions placed in front of them on the web site under a Clickwrap agreement (dashfarrow).

However, this does not make a Browse-wrap agreement completely unacceptable, since it is assumed that a customer who wants or is interested in a particular product wants to know his / her rights and with this website is obliged to place in a visible place the terms of the contract or to mention the link which indicates the terms and conditions of the contract.

As far as electronic contracts are concerned, in Kosovo they are not regulated by a separate law and are not mentioned in any law at all, so we can say that they are not protected by law, nor are they being used by businesses all this due to the economic isolation that Kosovo had until the beginning of 2016, when with the stabilization and association agreement, Kosovo was opened for the European market as well. 
Meanwhile, unlike Kosovo, the Republic of Albania is a step forward by regulating it with three separate laws, namely:

Law on Electronic Document (LDE)

This law regulates the use of electronic documents by natural, legal, public and private persons whose electronic programs and devices enable the realization, production, transmission, receipt, storage and security of electronic document information.

The Law on Electronic Signature (LNE)

The purpose of this law is to create the necessary legal framework for the recognition and use of electronic signatures in the Republic of Albania.

The Law on Electronic Commerce (LTE)

The purpose of this law is to establish rules for the conduct of electronic commerce actions, through the services provided by the information society, on the protection of the participants, the legal protection of the customer's confidentiality or the confidential data of the participants, and to ensure the free movement of information services, defining the responsibilities of the information society service provider.

\section{Electronic Signature}

"Electronic signatures" are all electronic data, which are are attached or logically associated with other electronic data, which serve as a way of certifying the signatory's identity and the authenticity of the signed document. An electronic signature is an electronic verification tool. This term is usually defined as a verification of the holder's identity. Any type of electronic verification shall be considered as an electronic signature as long as it is associated with other data in electronic form.

The term electronic signatures have been given a broad meaning and are specifically considered "electronic data, which are logically linked to other data electronically and serve as a verification method." These data may be code, picture, seals etc. Also, it should be clear that the term electronic signature is directly related to the verification of data and has nothing to do with actions such as using a PIN code to enter a bank account. Here we do not use electronic signatures. As you enter the same code to confirm a financial transaction, it's an example of data verification and is therefore considered an electronic signature. An advanced electronic signature is an electronic signature that meets the following 4 requirements:

I. It is affiliated uniquely with the signatory;

II. Is capable of identifying the signatory;

III. It is designed in such a way that the signatories have sole control over the signature;

IV. Relates to the data in such a way that any further change can be distinguished (guide). 
Whereas, qualified electronic signatures are advanced signatures but rely on a qualified certificate, thus issued by a legally recognized Certification Service Provider as such. For ease of use, it is called electronic signature. Also, it should be remembered that the signatory is not the person who creates the signature, but is the person who owns the signature creation device. An ordinary example of signature equipment is a smart card, flash drive, and so on.

The electronic signature can not be used in some specific areas, such as legal actions in the field of family law and inheritance, legal actions that require a public legalization, a notary act or requiring a court order.

The law does not extend to issues related to the validity and disruption of contracts or other legal obligations under the requirements set forth by other laws or by different states. An electronic signature is considered invalid if the security requirements foreseen in the law are not met (nolo).

To be as secure as an electronic signature, it should contain more or more difficult symbols or texts in order to avoid falsification or misuse, so consumers and businesses are hesitant or better to say that they are accessing this activity more difficult, but electronic signing and electronic contracts increase trust between businesses and between individuals and businesses as signing and signing an electronic contract and using an electronic signature should have a great deal of confidence, but this it also has a positive side as it reduces costs and costs, and also significantly increases efficiency and thus the efficiency of businesses increases significantly and the customer will be more satisfied. It should always be noted that extraordinary care has to be taken and the conditions of electronic contracts need to be read more carefully, as in recent years the potential abuse, electronic contracts and e-signatures have increased considerably as a consequence of the increasing popularity of electronic contracts electronic contract.

\section{European Union Directive on Contract and Electronic Signature:}

The European Union has implemented the model law through both directives; The Electronic Signature Directive and the Electronic Commerce Directive. Following the insistence of the European Commission, the European Union's directive was updated in 2000, after many researches and discussions, this directive has a total of 14 articles, the same directive was revised several times and updated in order to function as best as possible. to be as clear as possible what is contained in this directive of the European Union through this Directive, many countries have started and regulated their own domestic laws, ie they have harmonized the laws on electronic signature in relation to the directive of the European Union regarding the contract and the Electronic Signature, four annexes are included in this Directive, which clarify the content of the directives (Official Gazette). 


\section{Implementation of the directives:}

1. Member States shall adopt and implement by-laws, by-laws and administrative provisions which are necessary to comply with the legal obligations of this Directive before 19 July 2001. The Member States shall inform the Commission thereof. When adopting these measures, Member States shall mention the correlation between them and this Directive within the measures concerned or during their official publication. Methods for making this reference are determined by member states.

2. Member States shall communicate to the Commission the text of the main provisions of domestic law which they adopt in the field governed by this Directive (EU).

Major changes can be made since the entry into force of this directive, since since the entry into force of this directive the European Union has had a smaller number of states, and later with the addition of the number of members and with the increasing use of technology as technology advances, many other circumstances have changed as sophisticated tools for using information technology, and thus the potential misuse and risk of electronic signature management and electronic contracts have advanced to an extremely high level, and their use has increased too much, now many countries also have regulated through domestic legislation the use of electronic contracts and electronic signatures and as a result of this our modern society relies on an economic system based on the perpetrator is in the contract mechanism. For now, our industrial and service society is changing for a more modern and advanced society as well as access to information. One of the most important indicators showing this difference is the growing digital economy. But without any confidence of the economic community in electronic contracts, the new economy will not be able to reveal its full potential and good for our society, which will be behind the potential of new technology, what is capable of offer. Or we can build trust in technical solutions to contracts

Surely it is easier to create a technical solution for electronic contracts to be legally valid than to redefine a legal mechanism that exists since centuries, here it is about classical contracts. But on the other hand, a legal system that was generated thousands of years ago does not have the basics needed to incorporate modern communication modes, such as various modern contracting tools, such as electronic contracts and electronic signatures, we will need review the laws and draft a new law that would make the "Secure Electronic Contracts (Katarina), (SECO)" permissible and protected.

\section{E - Governance in Kosovo}

Electronic governance (rks-gov) is the provision of governmental services through information and communication technology (such as WAN, Internet, mobile network) to citizens, businesses and other categories. With the application of e-government, citizens and businesses, but also the government itself, will have effective and quick services, access to the service from every point and distance, stimulation of economic and social development, opportunities for capacity building, permanent services in any time, 
presentation of national achievements, etc. The Republic of Kosovo, being actively involved in the regional and European developments processes, will also engage in egovernment and ICT governance in the region and Europe. As a participant in international forums, Kosovo will realize all its obligations to develop the information society in full cooperation and partnership with the stakeholders. However, electronic governance does not only need European and regional integration but in particular we need to create a very important pillar of economic development and overall progress of Kosovo society(kryeministria).

Kosovo regarding electronic contracts and electronic signatures does not have a specific law, but for these in the strategy of the Government of Kosovo. Only in "E-Commerce" is writed that "e-commerce - Electronic commerce has to do with commerce that is carried out electronically using the Internet. This is closely related to the presentation of different products via the Internet (e-business) but by using the identity electronic can be realized electronic contracts of different sizes".

\section{Conclusion}

The rationale behind e-contracts is to enhance the operations of businesses today by providing faster and better means whereby transactions can take place without the parties having to leave their homes or meeting face to face. Considering this Kosovo has to create the law that regulate electronic contracts and electronic signature. A supplier can simply create a web site and advertise their goods and a consumer if interested can simply place an order through the web site and from that stage proceed to create a contract by following the necessary steps provided for him by the supplier to conclude a contract, this should start to be used more in our country becouase its more faster and easy to trade goods online than to wait untill kosovo has the visa liberations to travel to create contracts face to face.

An electronic contract is a contract concluded through electronic means. So apart from the form it seems that it has no distinction with classic contracts or regular contracts. The rights and obligations of the parties are the same, depending on the contract they bind, and by law in many countries are protected electronic form or electronic use, whereas regarding the contract as a contract in many states the defense refers to the civil code of the respective state, means its protection in case of dispute is made for those points that are not regulated by the law on the electronic contract and the law on electronic signature, the Civil Code states. The electronic contract has a very favorable approach towards globalization, or to the digitalization we are going to, as we see each other day, that we are moving towards a world of information technology, which means a world that favors everything related to digitalization, so the electronic contract is increasingly occupying a considerable amount of space on the world market due to the numerous commercial transactions being used precisely because of the advantages that this contract offers, as well as Speed and Flexibility are two of the the most specific features of the electronic contract, as the parties through it can enter into contractual 
relations in a very short time and agree on all the rights and obligations, and no matter where the world can to find one side or the distance between the sides no matter how 1 Arg may be parties can very easily conclude contracts through electronic contracts. Electronic contracts also have an extraordinary advantage, since through them or by utilizing them, parties can easily perform bank transactions at any time, thus eliminating many of the obstacles that have emerged beforehand. Problematic or negligent side the advantage of the electronic contract is first of all the scams or multiple chances of misusing the electronic signature and the electronic contract can be misused easily if only a little is not careful, so you should be very careful when using the electronic contract especially when using the signing electronic, using the most unique way for electronic signature.

\section{Bibliography}

[1] Nerxhivane Dauti, Contracts (for master studies), Prishtina 2012, pp.9-10.

[2] Nerxhivane Dauti, The Right of Obligations (General Part) Prishtina, 2004,

[3] Charles H. Martin, Every1's Guide to Electronic Contracts, 2013, p.28 Chap. 4

[4] https://papers.ssrn.com/sol3/papers.cfm?abstract_id=1948069 Ronald M. Lee, Decision Support Systems, Vol. 4, No. 1, 1988, pp. 27-44; date.01.04.2018

[5] All Answers ltd, 'E commerce and E Contracts' (Lawteacher.net, June 2018) <https://www.lawteacher.net/free-law-essays/commercial-law/ecommerce-and-e-contracts-commercial-law-essay.php?vref=1> accessed 19 June 2018

[6] https://www.batemanbattersby.com.au/electronic-contracts-electronicsignatures-valid/ Bateman Battersby Lawyers,(viewed on: 21 May 2018, 13: $35 \mathrm{~h}$ )

[7] All Answers ltd, 'E commerce and E Contracts' (Lawteacher.net, June 2018) $<$ https://www.lawteacher.net/free-law-essays/commercial-law/ecommerce-and-e-contracts-commercial-law-essay.php?vref=1> accessed 19 June 2018

[8] A Survey of Electronic Contracting Related Developments, "14th Bled Electronic Commerce Conference", Bled, Slovenia, June 25-26, 2001, p.497 (viewed: 29 February 2018, 23: 31h)

[9] BOLERO (Bills of Lading Electronic Registry Organisation) is a pilot project funded partially by the European Union in 1994. 'Bolero.net' is the legal structure for paperless international trade launched in September 1999. http://www.bolero.net/home/rulebook-and-title-registry/(viewed: February 2018, 20: 30h). 
[10] http://www.bolero.net/home/rulebook-and-title-registry/(viewed: February 2018, 20: 30h).

[11] All Answers ltd, 'E commerce and E Contracts' (Lawteacher.net, June 2018) <https://www.lawteacher.net/free-law-essays/commercial-law/ecommerce-and-e-contracts-commercial-law-essay.php?vref=1> accessed 19 June 2018.

[12] Mareike Schoop, Thesis type: PhD, http://dbis.rwthaachen.de/cms/theses/thesis-2

[13] A Survey of Electronic Contracting Related Developments, "14th Bled Electronic Commerce Conference", Bled, Slovenia, June 25-26, 2001, p.497 (viewed on February 2018)

[14] http://www.nolo.com/legal-encyclopedia/electronic-signatures-onlinecontracts-29495.html (viewed on 27 February 2018, 19: 30h)

[15] Michael Gisler "Legal Aspects of Electronic Contracts" Infrastructures for Dynamic Business-to-Business Service Outsourcing (IDSO'00) Stockholm, 5-6 June 2000 (viewed: 28 February 2018, 22: 19h)

[16] Mackenzie Hughes LLP, "Drafting Clickwrap and Browsewrap Agreements:Advanced Strategies for Enforceable Online Contracts"

[17] Charles H. Martin, Every1's Guide to Electronic Contracts, 2013, p.110 Chap. 3

[18] Guide to the Use of Electronic Signatures, Instruction no. 001, Bulletin September 2011, Version 1.3, Republic of Albania.

[19] http://www.nolo.com/legal-encyclopedia/electronic-signatures-onlinecontracts-29495.html (watched on: February 28, 2018, 01: 22h)

[20] (eu), Regulation 1999/93 / EC of the European Parliament and of the Council, Brussels, 13 December 1999 (as revised on 28 February 2018, 21: 22h)

[21] Katarina Stanoevska-Slabeva, Legal Aspects of Electronic Contracts, University of St. Gallen, https://pdfs.semanticscholar.org/fd12/b48c3c8fc96a0ca31137f62fdc93a9c2 e6c6.pdf

[22] (seco) Secure Electronic Contract (viewed on: February 30, 2018, 23: 22h)

[23] Electronic governance , https://map.rks-gov.net/institucion/Plan-andStrategies/Strategjia-e-e-qeverisjes.aspx?lang=en-US

[24] http://www.kryeministriks.net/repository/docs/STRATEGJIA_E_QEVERISJES _ELEKTRONIKE_2009_2015.pdf (viewed on: 28 February 2018, 24:06h)

[25] Electronic Document Law (LDE) ,Albanian Law. 
[26] Electronic Signature Law (LNE), Albanian Law.

[27] Law on Electronic Commerce (LTE), Albanian Law.

[28] Official Gazette L 013, 19/01/2000 p. 0012 - 0020, https://eurlex.europa.eu/legalcontent/EN/TXT/?uri=celex\%3A51998AG0326\%2803\%29 (watched on: 28 February 2018, 01: 22h)

[29] July 19, 2012, http://www.dashfarrow.com/website-agreements-browsewrap-vs-clickwrap-agreements/ (viewed on 28 February 2018, 20: 33h)

[30] July 19, 2012, http://www.dashfarrow.com/website-agreements-browsewrap-vs-clickwrap-agreements/ (viewed: 28 February 2018, 23: 33h)

[31] James Douglas, May 1, 2015, https://legalvision.com.au/click-wrapagreement-v-browse-wrap-agreement/ (viewed on: 27 February 2018, 00: 43h)

[32] Granit Curri, Kolegji Aab - paper- 2015, fq.8-9 